\title{
Enerji Verimliliği Sağlayan Yüksek Hızlı Hibrit Pişirme Fırını Tasarımı ve Prototip İmalatı
}

\author{
1,*Zafer Kahraman, ${ }^{1}$ Murat Hacı, ${ }^{1}$ Kadir İçibal ve ${ }^{2,3}$ Hakan S. Soyhan \\ ${ }^{1}$ Öztiryakiler Madeni Eşya San. ve Tic. A.Ş, Büyükçekmece, İstanbul, Türkiye \\ ${ }^{2}$ Team-SAN Ltd. Şti., Sakarya Üniversitesi, Teknokent, Serdivan, Sakarya, Türkiye \\ ${ }^{3}$ Sakarya Üniversitesi, Mühendislik Fakültesi, Makine Mühendisliği Bölümü, Sakarya, Türkiye
}

\section{Özet}

Şehirleşmenin sürekli artmasına bağlı yoğunlaşan hayat tarzının yemek alışkanlıklarında değişime neden olması ile hızlı yemek/ayak üstü (fast food) sektöründe kullanılan ürünlerde son yıllarda çok büyük gelişmeler görülmektedir. Bu sektörde mutfak ekipmanlarının da artan talebi karşılaması için hızlı pişirim teknolojileri uluslararası alanda önem kazanmaktadır. Ülkemizde ilk kez endüstriyel mutfak alanında konveksiyon ve mikrodalga sistemlerinin pişirilecek yiyeceğin türüne özgü eş zamanlı ve farklı güç ayarlarında çalışması başarılmıştır. Etkin pişirim sağlayan yenilikçi yüksek hızlı hibrit endüstriyel pişirme firını tasarım ve prototipi uluslararası standartlar (EN 60335-2-25 ve EN 60335-242) doğrultusunda özgün proje çalışmaları ile elde edilmiştir. Yenilikçi prototipin davlumbaz kullanılmadan etkin çalışması ve enerji tasarrufu da sağlaması Ar-Ge çalışmaları ile başarılmıştır. Yüksek hızlı ve hibrit çalışma yönünde bilgi birikiminin artırılmasına katkı sağlaması yanısıra etkin pişirim sağlayacak yenilikçi hibrit endüstriyel mutfak firının yaygınlaştırılması için ivme kazandırıcı ve yönlendirici bilimsel veriler elde edilmiştir.

Anahtar kelimeler: Enerji verimliliği, Yüksek hızlı pişirim, Endüstriyel mutfak, Mikrodalga, Konveksiyon, Hibrit firın.

\begin{abstract}
The recent developments in the fast-food sector have seen tremendous developments in the food industry due to the fact that the lifestyle that is concentrated on the continuous growth of urbanization causes a change in the eating habits. In this sector, rapid cooking technologies are gaining importance in order to meet the increasing demand of kitchen equipment. For the first time in our country, convection and microwave systems in the industrial kitchen area have been achieved to work simultaneously and in different power settings specific to the type of food to be cooked. The innovative design and prototype of the innovative high-speed hybrid industrial cooking oven providing efficient cooking has been achieved with original project studies in line with international standards (EN 60335-2-25 and EN 60335-2-42). R\&D studies were carried out to ensure that the innovative prototype works effectively without the hoods and to provide energy savings. In addition to contributing to the increase of knowledge in the high-speed and hybrid working direction, there is also scientific data to accelerate the introduction of an innovative hybrid industrial kitchen oven that will enable efficient cooking.
\end{abstract}

Key words: Energy efficiency, High speed cooking, Industrial kitchen, Hybrid owen, Microwave, Convection. 


\section{Giriş}

Endüstriyel mutfaklarda pişirme fırınları yoğun olarak kullanılmaktadır. Ar-Ge sistematiği ile yapılan çalışmalarla mevcut endüstriyel pişirme fırınlarından farklı olarak ülkemizde ilk kez pişirim sürecinde konveksiyon ve mikrodalga sistemlerinin eş zamanlı ve farklı güç oranlarında kullanarak etkin ve yüksek hızlı pişirim sağlayan yenilikçi hibrit endüstriyel yemek pişirme firın sistemi uluslararası standartlar (EN 60335-2-25 ve EN 60335-2-42) doğrultusunda geliştirilen ve davlumbaz kullanımı gerektirmeyen özgün tasarımlı yenilikçi prototip elde edilmesi proje çalışmalarının en önemli yenilikçi (inovatif) yönünü oluşturmuştur.

Yapılan literatür incelemelerinde, mikrodalga sistemleri ile ilgili mikrodalga teknolojilerinin yiyecek endüstrilerinde uygulamaları ve matematiksel analizler üzerine çeşitli çalışmalar olduğu belirlenmiştir [1-3]. Geedipalli ve ekibi tarafından mikrodalga fırınlarının çok popüler olmasına rağmen düzensiz 1sıtma, aşırı 1sıtma vb. olası problemlerden dolayı daha farklı firınların tercih edildiğini bildirmişlerdir. Mikrodalga sistemlerinin çeşitli pişirme yöntemleri ile entegre olabileceğini ve seçim yaptıkları aşağıdaki hibrit firın üzerinde değerlendirmelerde bulunmuşlardır. Birleşik sistemli modun (mikrodalga ve hava sıkıştırmalı) yalnızca mikrodalganın kullanıldığı sisteme göre \%22-30 oranında tekdüzelik (uniformity) sağlandığını belirtmişlerdir [4]. Ruocco ve ekibi tarafından mikrodalga sistemi ile bölgesel konveksiyonun birlikte uygulanması durumunda nemli ve gözenekli yüzeylerde 1sıtmanın etkileri ile iyileştirme yönünde veriler elde ettiklerini bildirmişlerdir. Mikrodalga ile uzun süre yiyeceğin maruz kalması yiyeceğin atının nemlenmesine neden olacağını bu nedenle mikrodalga ve bölgesel konveksiyonun entegre olarak uygulamasının yiyecek kalitesi üzerinde birçok parametre (iç ve dış ısıtma, kütle transfer mekanizması vb.) ile değerlendirilmesi gerektiğini bildirmişlerdir [5]. Marra ve ekibi tarafından mikrodalga ve konveksiyon ısıtma sistemlerinin entegre olarak süreç iyileştirme faaliyetleri için çeşitli uygulamalarda kullanılmasına yönelik çalışmalar yürütmüşlerdir. Bölgesel sıcaklık dağılımları üzerinde hava hızı ve işlem süresinin etkilerini CFD (Computational Fluid Dynamics) ile değerlendirmişlerdir. Deneysel çalışmalarında yiyecek numunesini Ls ve Hs ebatlarını tanımlamışlardır ve kurutucu boşluğunda mikrodalga ve hava kurutucu konveksiyon sistemini beraber uygulamışlardır. Farklı sürelerde oluşan sıcaklık değişimlerini modelleme ile değerlendirmişlerdir [6]. 


\section{Metot}

\subsection{Tasarım}

Endüstriyel firınların ana amacı kısa sürede ve etkin pişirme sağlamaktır. Bu bildiride sunduğumuz "hibrit endüstriyel firın" mevcut konvansiyonel firına mikrodalga sistem entegrasyonu şeklinde geliştirilmiştir. Etkin pişirim sağlayan yenilikçi yüksek hızlı hibrit endüstriyel pişirme fırın prototipinin teknik çizimi Şekil 1 ve 2'de verilmiştir. Geliştirdiğimiz “hibrit endüstriyel firın”'1n ısıtma toplam kapasitesi 5 kW'tır. Alt kısımda 5-6 devir/dk'da dönen bir tabla yer almaktadır. Prototipin çalışma sıcaklığ 1 aralığ $195^{\circ} \mathrm{C}$ ile $280^{\circ} \mathrm{C}$ 'dir. Konveksiyonel firın kısmında iki adet rezistans $(1500+1500 \mathrm{~W})$ ve mikrodalga bölümünde iki adet magnetron $(1000+1000 \mathrm{~W})$ mevcuttur. İç haznenin arka kısmında fan yerleştirilmiştir. İki tip tasarım yapılmıştır:

1.tip: 2 x $1000 \mathrm{~W}$ magnetron 2 x $1500 \mathrm{~W}$ rezistans 1 sitıc1

2. Tip 2 x $1000 \mathrm{~W}$ magnetron $3000 \mathrm{~W}$ turbo fanın çevresine konumlanmış rezistans

Sıcak hava sirkülasyonu $200 \mathrm{~m}^{3} / \mathrm{h}$, frekans: $50 \mathrm{~Hz}$ ve hız $12000 \mathrm{dev} / \mathrm{dk}$ olarak seçilmiştir.

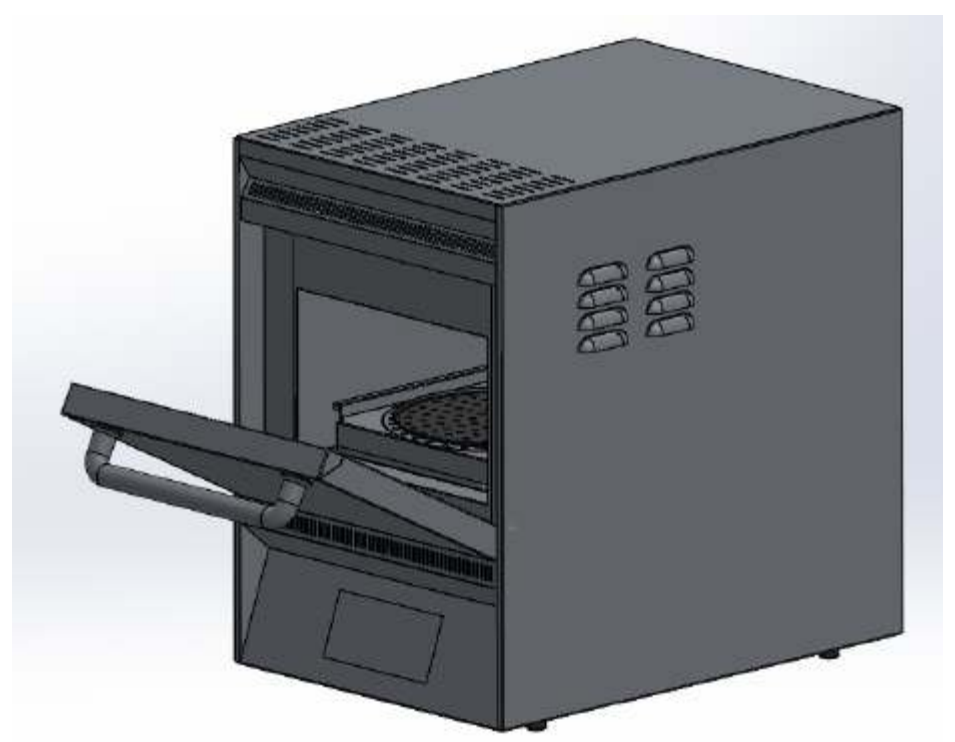

Şekil 1: Etkin pişirim sağlayan yenilikçi yüksek hızlı hibrit endüstriyel pişirme firın prototipi teknik çizimi. 


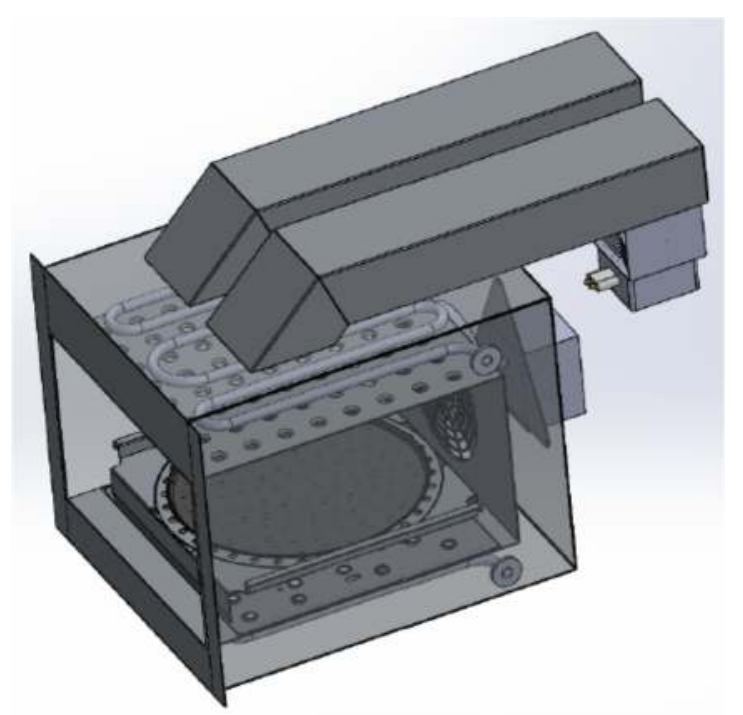

Şekil 2: Yenilikçi prototipin pişirme iç haznesi.

2.2. Simülasyon Çalışmaları

Enerjiyi verimli kullanmak, doğrudan ürün ve işletme maliyetlerini azaltırken, dolaylı olarak da enerji tüketiminden kaynaklanan emisyonları azaltmaktadır. Bu şekilde optimize edilmiş bir tasarım elde etmek için tanımlanan sıcaklık sınır şartları ve ısı geçişi katsayıları kullanılarak fırın içindeki sıcaklık dağııımını ve hızını bulmak için fırınnın modeli kurulmuş (Şekil 3) ve ısıl analiz yapılmıştır.

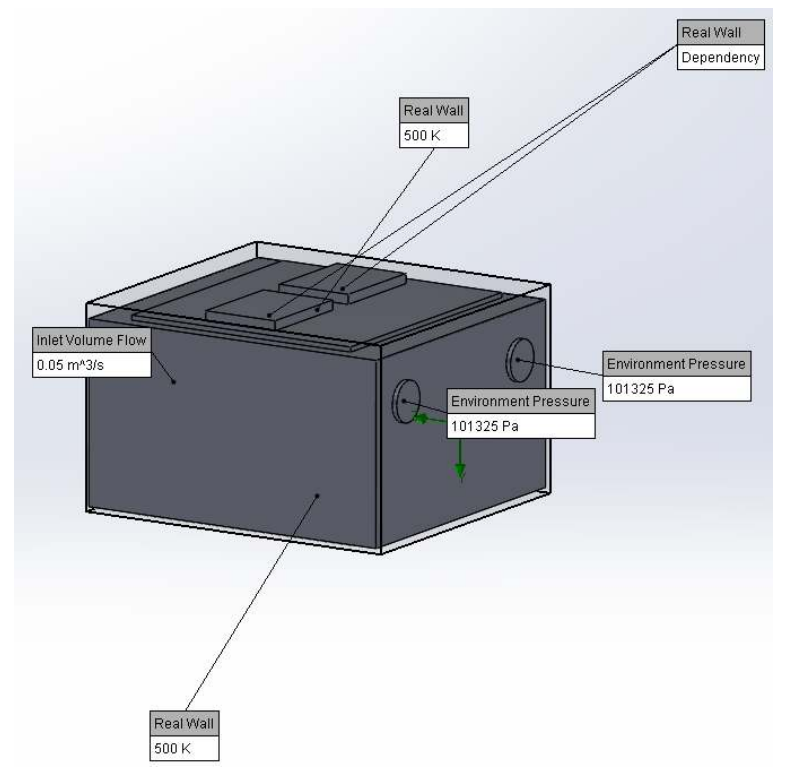

Şekil 3: Yenilikçi prototipin simülasyon için hazırlanmış analiz modeli. 
Analiz kapsamında sistemin performansını etkileyen parametreler tanımlanan kısıtlar ve çalışma koşulları için parametrik olarak çalışılmış ve sistem üzerinde yapılması gereken iyileştirmeler ve alternatif tasarımlar belirlenmiştir.

Ön ısıtmasız sistemde ilk analiz öncelikle konvansiyonel tip elektrik fırın için yapılmıştır. 180 saniye çalışma süresi belirlenmiş olup fırın içerisindeki hacme $400 \mathrm{~K}$ sıcaklığında ve $0.5 \mathrm{~m} / \mathrm{s}$ hızda sıcak gönderilmiştir. Analiz sonuçlarına göre sadece elektrikli ısıtıcı devreye girdiğinde 180 saniyede fırın içerisi $83^{\circ} \mathrm{C}$ ye ulaştığı gözlemlenmiştir.

\begin{tabular}{|l|l|l|l|l|} 
Name & Current Value & Progress & Criterion & Averaged Value \\
\hline GG Av Temperature (Fluid) 1 & $356.664 \mathrm{~K}$ & Achieved (IT = 221) & $3.68831 \mathrm{~K}$ & $356.648 \mathrm{~K}$ \\
\hline
\end{tabular}

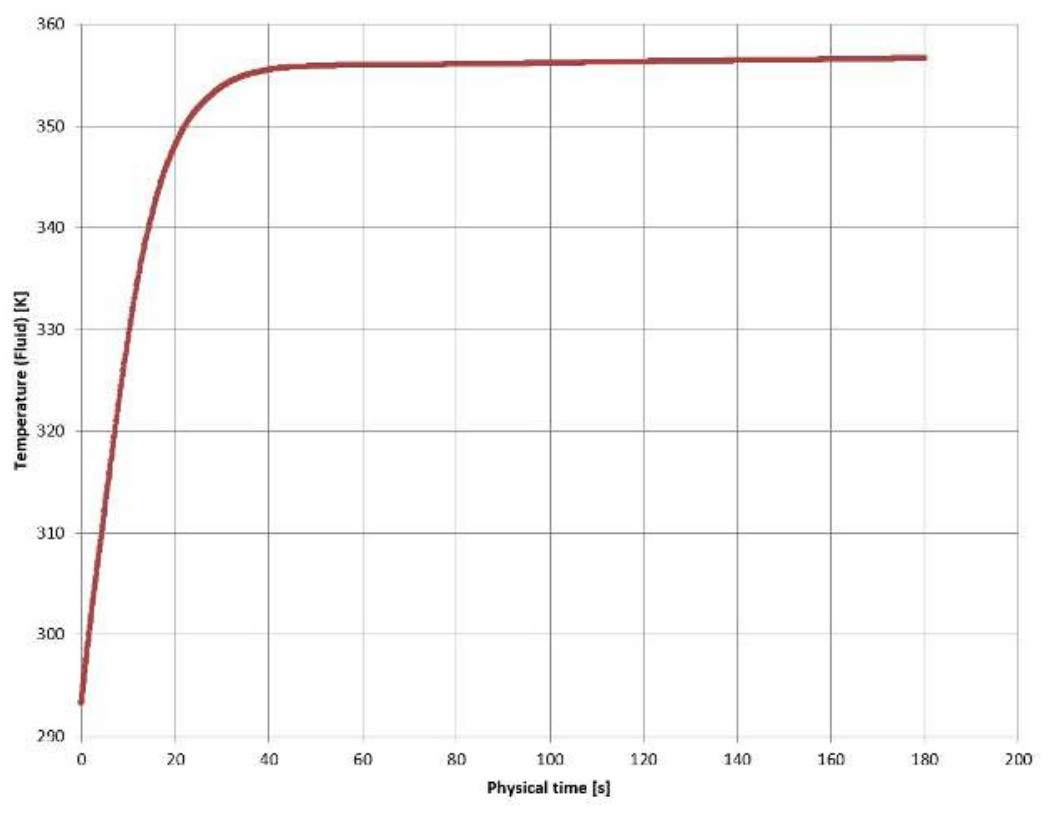

Şekil 4: Yenilikçi prototipin sadece rezistanslı durum için sıcaklık ve zaman eğrisi.

Sadece mikrodalga opsiyonu kullanıldığında ise fırın içerisindeki hacme $1200 \mathrm{~W}$ gücünde bir mikrodalga kaynağı eklenmiştir. Analiz sonuçlarına göre sadece mikrodalga devreye girdiğinde 180 saniyede fırın içerisinin ön ısıtmasız durumda $94{ }^{\circ} \mathrm{C}$ ye ulaştığı gözlemlenmiştir (Şekil 4).

Karma tip fırın için ise 180 saniye çalışma süresi belirlenmiş olup, fırın içerisindeki hacme $1200 \mathrm{~W}$ gücünde bir mikrodalga kaynağı ve $400 \mathrm{~K}$ sıcaklığında ve $0.5 \mathrm{~m} / \mathrm{s}$ hızda sıcak hava eklenmiştir. Analiz sonuçlarına göre karma sistem devreye girdiğinde 180 saniyede fırın içerisinin $100^{\circ} \mathrm{C}^{\prime}$ ye ulaştığı gözlemlenmiştir. 


\begin{tabular}{|c|c|c|c|c|}
\hline Name & Current Value & Progress & Criterion & Averaged Value \\
\hline GG Av Temperature (Fluid) 1 & $367.734 \mathrm{~K}$ & Achieved (IT $=440$ ) & $2.36341 \mathrm{~K}$ & $367.607 \mathrm{~K}$ \\
\hline
\end{tabular}

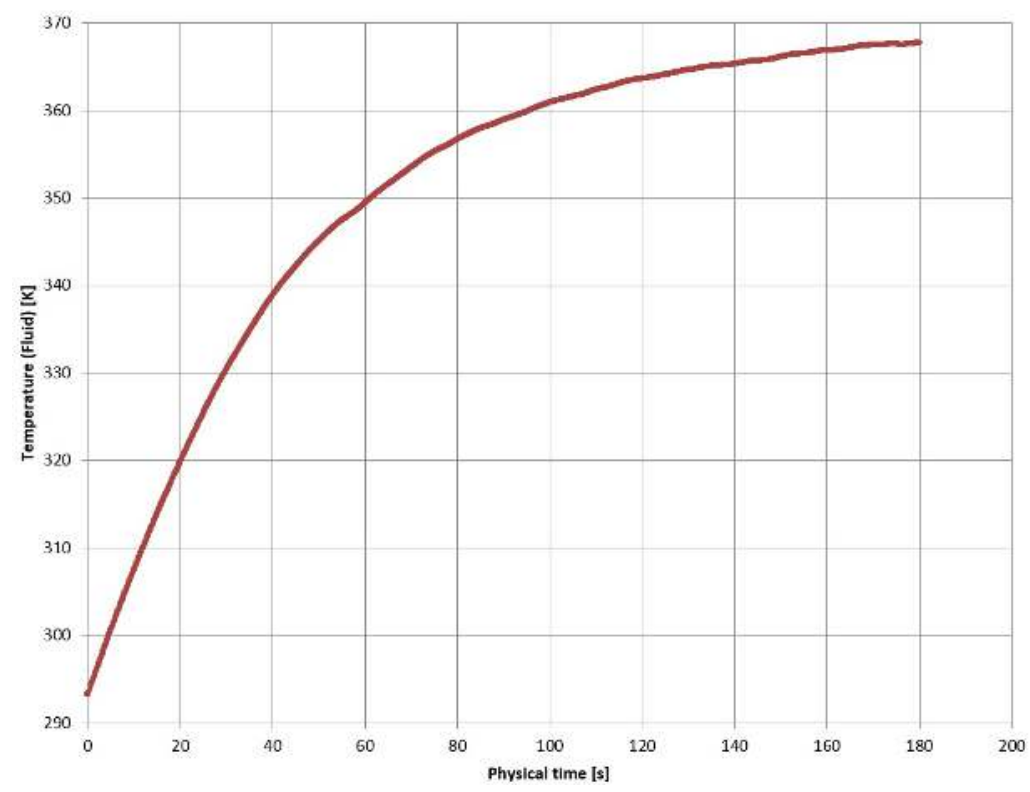

Şekil 5: Yenilikçi prototipin sadece mikrodalgalı durum için sıcaklık ve zaman eğrisi.

\begin{tabular}{l|l|l|l|l} 
Name & Current Value & Progress & Criterion & Averaged Value \\
\cline { 1 - 2 } GG Av Temperature (Fluid) 1 & $373.841 \mathrm{~K}$ & Achieved (IT =225) & $4.75178 \mathrm{~K}$ & $373.839 \mathrm{~K}$
\end{tabular}

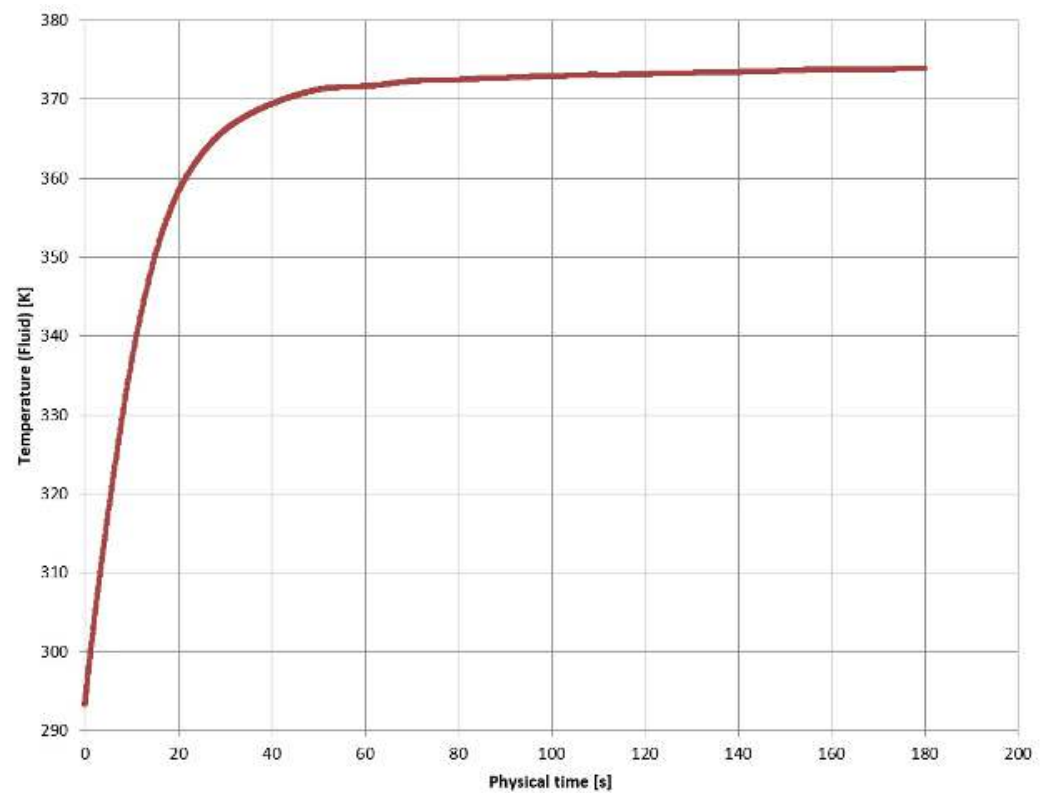

Şekil 6: Yenilikçi prototipin hibrit durum için sıcaklık ve zaman eğrisi. 
Bu sonuçlar ışığında geliştirdiğimiz hibrit fırının ilk çalışmada ön ısıtma prosesi kapsamında 900 saniye sadece konveksiyonel kısım ile ısıtılmasına karar verilmiştir. Yenilikçi prototipin ön ısıtmalı (900 saniye) halde sadece rezistans ile sıcaklık dağılımı Şekil 7-8'de verilmiştir. Karma sistemin performansı ise Şekil 910 'de verilmiştir. Görüldüğü üzere fırın içi sıcaklık karma sistemde artmıştır ve prototipin hedeflenen değerine ulaşmıştır.

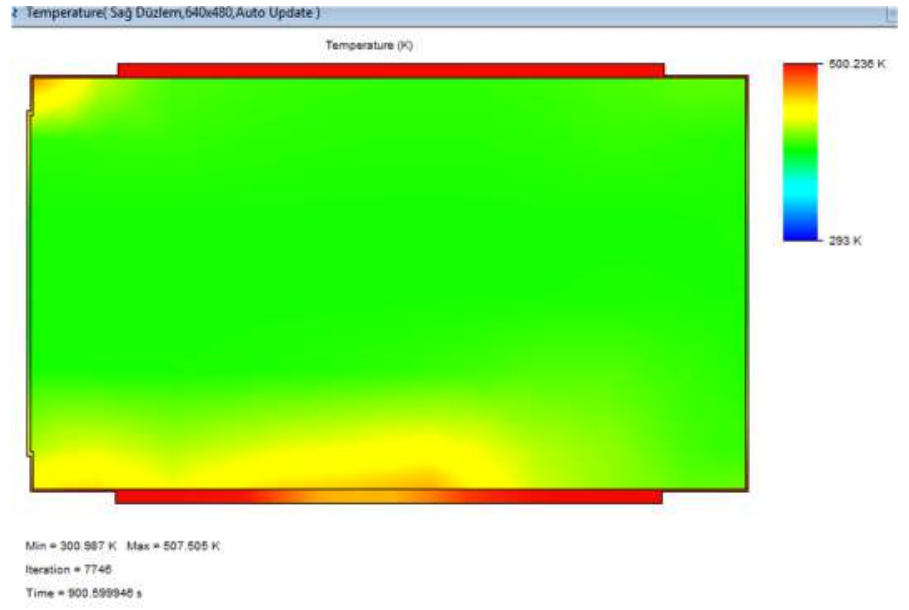

Şekil 7: Yenilikçi prototipin ön 1sıtmalı (900 saniye) halde sadece rezistans ile sıcaklık dağılımı

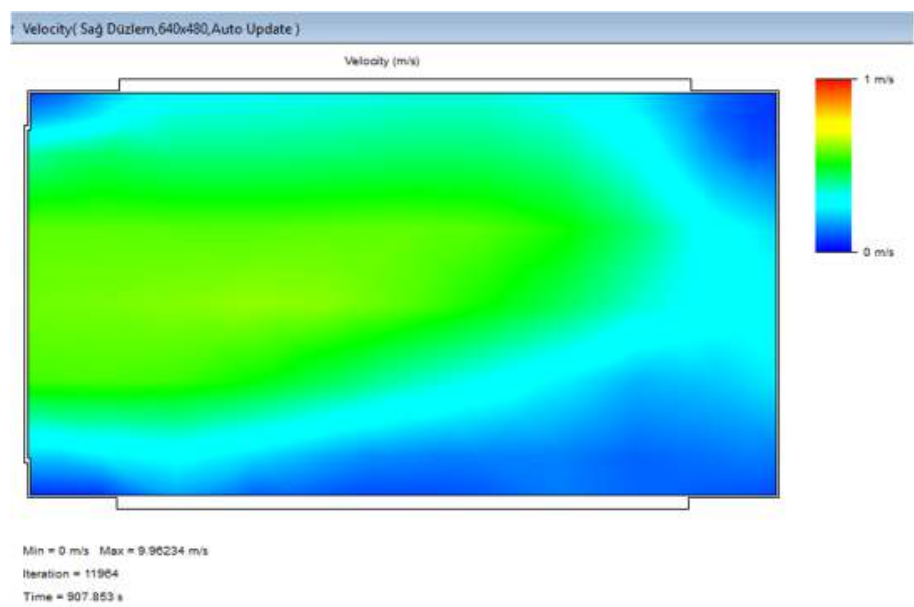

Şekil 8: Yenilikçi prototipin ön 1sıtmalı halde sadece rezistans ile ısıtmada hız dağılımı. 


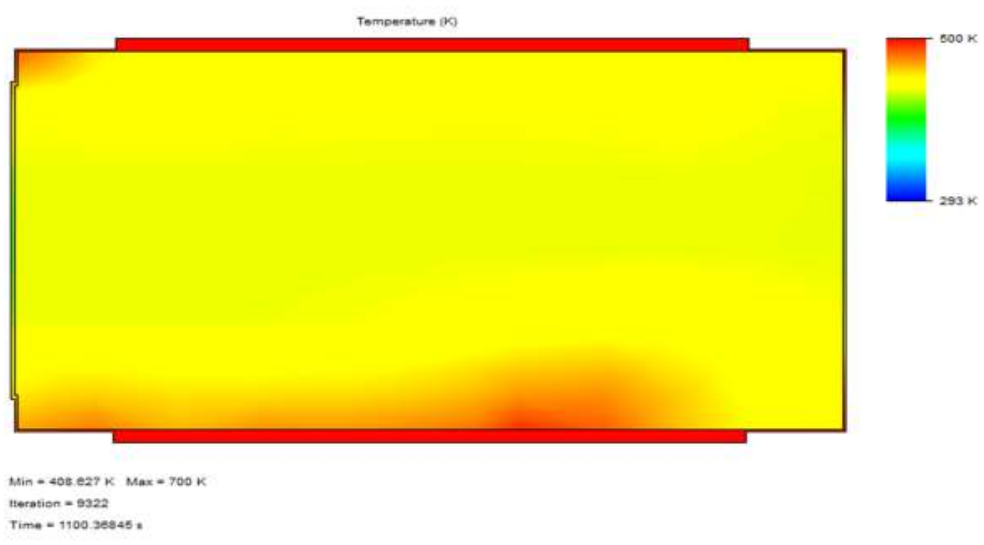

Şekil 9: Yenilikçi prototipin ön ısıtmalı halde rezistans ve mikrodalga kombinasyonu ile sıcaklık dağılımı.

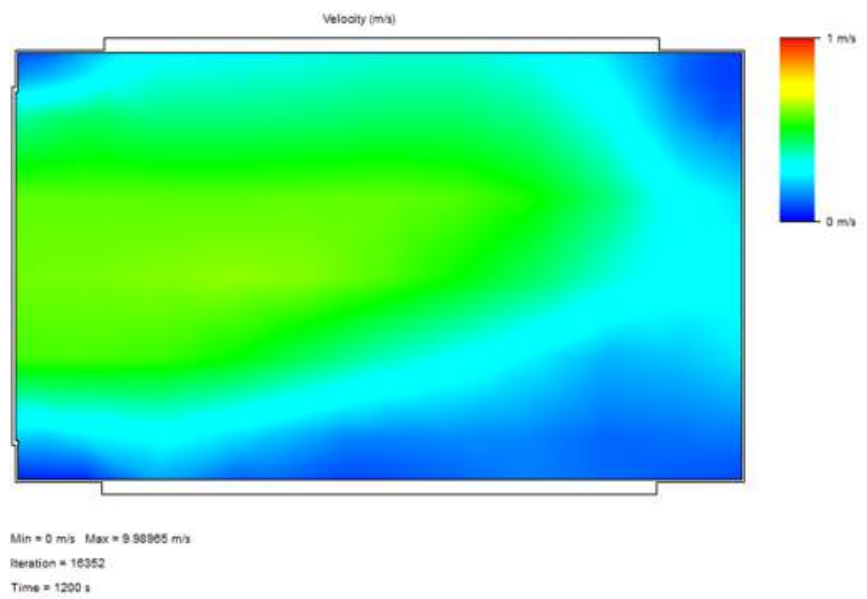

Şekil 10: Yenilikçi prototipin ön ısıtmalı halde rezistans ve mikrodalga kombinasyonu ile hız dağılımı.

\section{Sonuçlar}

Ar-Ge sistematiğine dayanan çalışmalarla endüstriyel mutfak alanında ülkemizde ilk kez konveksiyon ve mikrodalga sistemlerinin eş zamanlı ve farklı güç oranlarında kullanılmasına yönelik etkin pişirim sağlayan yenilikçi yüksek hızlı hibrit endüstriyel pişirme firının özgün tasarımı ile prototip imalatı bilimsel veriler ile sağlanmıştır. Sanayi-üniversite işbirliği ile yürütülen çalışmalar, özgün tasarımlı yenilikçi prototipin elde edilmesine önemli veriler sağlamıştır. Mühendislik hesaplamaları ve simülasyon çalışmaları ile ticarileşebilecek yenilikçi prototipin elde edilmesi uluslararası rakiplerle rekabet edebilirliğimize katkı sağlamıştır. 


\section{TEŞEKKÜR}

Bu çalışma, TÜBİTAK-TEYDEB 1501 kodlu Sanayi Araştırma Teknoloji Geliştirme ve Yenilik Projeleri Destekleme Programı kapsamında "Etkin Pişirim Sağlayan Yenilikçi Yüksek Hızlı Hibrit Endüstriyel Pişirme Fırını Tasarımı ve Prototip İmalatı” başlıklı ve 3170718 numaralı proje çalışmasından hazırlanmıştır. TÜBİTAK-TEYDEB Ulaştırma, Savunma, Enerji ve Tekstil Teknolojileri Grubu'na (USETEG) proje çalışmalarına sonsuz katkılarından dolayı teşekkür ederiz.

\section{KAYNAKLAR}

[1] Orsat, V., Raghavan, G.S.V., Krishnaswamy, K., Microwave technology for food processing: An overview of current and future applications, The Microwave Processing of Foods (Second Edition), 100-116, (2017).

[2] Pace, M., De Bonis, M. V., Marra, F., Ruocco, G., Characterization of a combination oven prototype: Effects of microwave exposure and enhanced convection to local temperature rise in a moist substrate, International Communications in Heat and Mass Transfer, 38 (5), 557-564, (2011).

[3] Campañone, L.A., Zaritzky, N.E., Mathematical analysis of microwave heating process, Journal of Food Engineering, 69 (3), 359-368, (2005).

[4] Geedipalli, S., Datta, A.K., Rakesh, V., Heat transfer in a combination microwave-jet impingement oven, Food and Bioproducts Processing, 86 (1), 53-63, (2008).

[5] Marra, F., De Bonis, M.V., G. Ruocco, G., Combined microwaves and forced convection heating: a conjugate approach, Journal of Food Engineering, 97 (1), 31-39, (2010).

[6] Ruocco, G., De Bonis, M. V., Marra, F., Combining microwave and jet-impingement in a oven prototype, Procedia Food Science, 1, 1331-1337, (2011). 